\title{
The World Miraculous Characters in the Dream - the Interesting Symbol in Vietnamese Fairy Tales
}

\author{
Nguyen Thi Dung \\ Department of Inspect, University of Labour and Social Affairs, Hanoi City, Vietnam \\ Email address: \\ dungcamg@yahoo.com \\ To cite this article: \\ Nguyen Thi Dung. The World Miraculous Characters in the Dream - the Interesting Symbol in Vietnamese Fairy Tales. International \\ Journal of Language and Linguistics. Vol. 6, No. 1, 2018, pp. 24-30. doi: 10.11648/j.ij11.20180601.15
}

Received: January 26, 2018; Accepted: February 16, 2018; Published: March 8, 2018

\begin{abstract}
Currently, the world has grown deep concern of the issue of symbols. The symbol has become popular research direction and has made certain achievements in the interactive language issues - literature - culture, especially in folklore studies. In the course of research on sub-type miraculous fairy tales Vietnam, the author found that the world miraculous characters (WMC) in the dream appeared with frequency bearing dense and symbolic meaning. That is to say, the WMC is a symbol interesting. This dream of fairy tales characters is a mystical symbol, universal, all humanity. So, the "WMC in the dream" is a kind of "dream cage dream", "symbol cage in the symbol" should be "decoded" in order to understand the intellection of art about people and the world that the folk authors expressed therein. The author would like to say about its deep influence on the development of WMC in the fanciful literature. In this paper, the researcher will survey of the world series with vanity; classification survey data; mentioned is the symbolism of the world vanity; grasp the concept of the ancient art of the world, humans.
\end{abstract}

Keywords: Characters, Miraculous, Devil, Fairy, Dream, World

\section{Introduction}

The issue of miraculous dream is interesting but not much researched in Vietnam. The author's work is the first work to go into the overall study, the systemealier, Alain Gheerbrant had a very interesting comments as follows: "Saying that we live in a world of symbols, it is still not enough, to tell the world a living symbol of us, this truly" [1]. WMC and the miraculous world in the dream is the "world of the symbolic" as such.

WMC include: Holy, Gods, Devil, Fairy, Buddhism Buddha, Dragon King, etc... poetic symbols and iconic. These symbols may have "many layers of depth and meaning, hard to explain once and for all". Each symbol in a dream world which has" the homogeneity between the expression and what is expressed [1].

Gods, Holy, Fairy, Devil, Buddhism - Buddha, etc... are deeply rooted in the culture and spiritual beliefs of the nation's oldest in religion. The first sign to form symbolic world in general and the "world symbol" in particular is a dream primitive notions, represents the original form of the class "strata" recesses of the subconscious and instinct human. In the process of living, to account for these things, mystical phenomenon around... and people were assigning them their subjective idea and see it as a convention to distinguish. At each different era, man has conceived and explainted things, to understand the phenomenon of differently.

So, WMC are symbols like the river deposited sediment layers that deposition in which multiple layers of culture. To "decode" the symbol, requires people to explain the origin of cultural layers - the first starting point to form the kind miraculous characters.

WMC is a form of expression of the world symbol: it bears the full characteristics of the world.

First, WMC is "the visible sign bearing a lead us to the invisible" [1]. "The visible" (the expression) here is the miraculous characters, and "the unseen" (what was expressed) is the manifestation of the "underlying idea" inside miraculous characters.

"Content manifestation" of miraculous characters are images, activities and characteristics of the miraculous characters as God, Holy, Fairy, Buddhism - Buddha, Devil, Goblins, etc... appeared in the fairy -tales.

"Underlying idea" in WMC always hidden behind the "manifest content" is the miraculous characters. It is the dream, 
the intellection of art, etc... WMC governs the formation of "the content of your dreams expression" of the ancients.

"Contents of expression" in the miraculous characters are quite rich expression. For example, when talking about the God, Holy, Fairy, Buddhism - Buddha, etc..., people think that the characters have multiple licenses, gentle, human weather, or help people. This deep roots from the "underlying idea", the dream of human life changed. They always wish to have happy life, immortality... To understand the "underlying idea", they have to "decode" "manifest content" of the miraculous characters.

To explain the appearance of the miraculous characters, the author must use the "symbol to symbol explanation". Animated symbol comes from the consciousness of the people and their environment. The system of spiritual instruction is of God, or Buddhism - Buddha... but also the human. The instructions that sometimes still "closed". To explain it, sometimes the reseacher have to rely on the habitat.

One of the characteristics of the symbol is "simultaneity of the meaning... it evokes an mutual penetration between them" [1]. The main characteristics that co-present symbol of miraculous characters are multidimensional. Of course, each character contained in its own symbolic meaning. The author will learn the meaning of each type miraculous characters logo detail.

\section{Materials and Methods}

The author has applied the methods such as: statistical methods, literature review; comparative method; systematical approach; analytical method; synthetic method; interdisciplinary approach to deploy the topic:

\subsection{Statistical Methods}

Researcher set the miraculous fairy tales book typical of the people of Vietnam have been published. Then, read all the books and stop at the miraculous characters. On this basis, the author statistics, sorting them

\subsection{Comparison Method Type}

In the process of researching the subject, the author will compare the resources to see the characteristics of each type miraculous characters. On that basis, the author use this kind of method to find out the similarities and differences of WMC; simultaneously, confirming the origins and characteristics and values of WMC.

\subsection{Method System}

Regarded WMC is a complete system, the researcher use a systems approach to understand the component parts of it. Method system has a key role for the type miraculous characters survey, miraculous characters criteria: the origin, nature, action, function, impact and so on...

\subsection{Synthetic Analysis Method}

WMC will be author's division into type, character types with different functions. The researcher will analyze each of them specific expression. When analyzing the material, researcher chose the typical evidence that WMC and finally draw comment, integrated assessment.

\subsection{Interdisciplinary Methods}

The author use interdisciplinary methods (ethnographic, cultural practitioners, psychiatrists, religious school, etc...) to explain the aesthetic conception of the origin of WMC.

\section{Results}

In this context, the author conducted a survey of the world series with vanity; classification survey data; mentioned is the symbolism of the world vanity; grasp the concept of the ancient art in the world, humans.

The first is about conducted a survey of the world series with vanity; classification survey data; mentioned is the symbolism of the world vanity:

In the world of vanity, the author is interested in symbols as: Devil, Fairy, King of Ocean, King of River, Deity, animals, plants, etc... The researcher will explore the symbolism of this miraculous characters.

Devil: According to the most common interpretation, the devil (in general) is: "The soul is about, according to superstition," [2]. In the belief, ghosts, demons are not totally symbolizes evil, but when in folklore (folk) often is evil. The devil is the general character of the two types of ghosts and demons. Devils have a lot of categories such as: Yaksa, devil, etc... According to a research topic of the author's other, demons occupy character number as 41/90, accounting for $45.5 \%$ and the frequency of occurrence is 76/191 times, accounting for $39,9 \%$; followed by ghosts, whose number is: $22 / 90$ characters, representing $24.44 \%$ and frequency are: $56 / 191$ times, accounting for 29,31\% [3].

When it comes to spirits, the devil, the ancient Greeks had the notion: "spirits are divine beings or have a certain power, like the gods. Later, the term was used to refer to those inferior gods and finally to only those spirits demons... also dead souls, is the patron or scary, intermediaries between mortals and immortals live but will die... spirits are separate beings exist and abound, reeling everywhere, doing all things good and bad things... " [1].

They also distinguish evil spirits as follows: "... the devil symbolizes all the power disruptor, as shady, weakened conscience and receding of uncertainty and bisexual doubleway value: is the center of night, in opposition to God is the center of light" [1].

In the opinion of the peoples, in anywhere that demons appear, they also brought disaster, uncertainty in people. Devils are the embodiment of evil are present throughout the human world. Demon symbolizing the terrible, frightening, evil:

In the stories: Four suffering souls, Two lump (Viet) [4], the demon is common in the deserted temples, deserted, in wet jungle to prowl, to eat human flesh. Devils became the terror of the human mind and they always want to stay away.

Devils do not appear only on earth but also in heaven (Mrs 
Hoa Vai) [5]. In the intellection of Ede ethnic, the devil's child of God has come into the wildlife and to fool and catch humans on earth to wife. If the devil is evil, aggressive willing to eat all the meat your child, chasing people down to the type of green demon broke his back broken hearted devils are gentle, kind, indications Hoa Sach to find the whereabouts of his wife.

So, in the minds and a common notion of the demon folk always become a symbol of evil. Usually associated with demonic ghost types:

Ghost in Cock turned into evil ghost, Ghost revenge (Viet), symbolizing the souls of the dead, often on earth is about. Ghost also often sought revenge, bring disaster to the people.

Aside from the evil ghost, symbolizing evil, there are ghost pitiful, precious. This is the soul of the man, but noble qualities that have to suffer the injustice of sight needs to be clarified. The ghosts were invaluable help earthly people accomplish career aspirations, career, love, happiness (Current pupil ghost shape, Human married ghost...).

If the story of the Vietnamese people, ghosts are often unfairly longtime soul of the deceased in the story is about the ethnic minorities of the miraculous characters was killed, and another was rescued miraculous characters right back with miraculous, magical:

Mrs H'bia Phu (Mrs H'bia Phu beautiful) [6] was the daughter of the god of water. She has beautiful, and talent to weave cloth. H'bia Phu married to the mortal. To rob her as his wife, hawk began losing her soul. Mr Rit has defeated him hawk and bring the soul of his wife on earth. Grany Pom is used aging miracle so she has risen and become more beautiful than before. So, the concept of ethnic minorities but here is the $\mathrm{Chu} \mathrm{Ru}$, man lost souls caught even while alive. Ghosts and souls of men are related intimately to rebirth; a symbol of rebirth. Rebirth by wondrous miracles. The spirit of this type are usually ghost healthy, not harmful to humans.

In the story Mrs Cu Pen [7], her soul and Dao Lu's met at the village of God. In the intellection of the Ta Oi ethnic, heaven village is a place for the souls of the dead reside, meet. This is also a place for people who love each other but can not get to come to your feelings and stay together after death.

The miraculous characters demons are formed in the imagination and perceptions associated with the ancient art of a bulb, to cause people to have an insight on life, thanks to the interlocking between real and virtual, sound and ocean, past and present. Permanent devil in human consciousness, with dreams and aspirations endless.

Hades, goblins, ghosts, etc...derived from popular beliefs, from the concept of "animism" (all things have souls) of man. The devil is common in the limbo, which is eternity for the dead. The earth is a place to contain the variant form of, revived; the process from death to life. Sometimes the miraculous characters put the protagonist, villain to Hades as punishment or deterrence, there are times, Hades the human assistance, enabling people could meet again or put the their loved ones on the ground (Realize mother tongue, White chicken and copper ring...).
Belief in ghosts is the belief of the human spirit to the afterlife, is the desire to continue life after death. Since ancient times, people lived in a closed world, they are almost no absolute separation between the living and the dead realm. After the man died, the devil (soul) continues to live in the earthly world. Since Buddhism appeared the reincarnation of Buddhism combined with folk beliefs have actually led to the death (the devil) is recycled back to people. Reconstruct images in the system demonic tales, ancient people also through which to lend to inculcate evil people wish they shun evil, do evil.

Heaven is a direct expression of authority, of the eternal, sacred; which is not a thing on earth can be achieved. "Symbol of God are often the symbol of the father, in whose jurisdiction, of omnipotence,"... [8]. This means that God, Giang, etc... Then there are also the non-feature often that people crave to learn.

World symbolizes heaven above, belong to the Heaven. Of the 214 miraculous characters belongs Heaven, 18 characters is Giang, Then (as the characters ruled the sky), representing $8,41 \%$ [14]. The remaining characters belong to God is the son of God, daughter of God, the heavenly God, minister of God, a servant of heaven, etc...

God, Giang, Then, etc... just appear magically fairy tales ethnic minorities who do not appear in the story of the people of Vietnam. This may stem from the concept and name a character is God's peoples. In the intellection of the Vietnamese, the Ngoc Hoang (Jade Emperor) was considered the ruler of Heaven, of the world on high. And the notion of ethnic minorities, Heaven, Giang, etc... Then was the king of heaven, who dominated and ruled the skies.

Heaven, Giang, Then, etc... often male and have absolute authority. The last miraculous characters help this man, just hinder them:

Heaven (Fabulous Fan) of Gia Rai ethnic character is sympathetic with the people should have helped them cross above the river. Or as God (Brothers Prong Pha) of Ede ethnic is the image of the merciful father, has allowed miraculous metamorphosis, help for their childs. Giang (Mrs $\mathrm{Cu}$ Pen) of the Ta Oi ethnic, Giang (Mr Ca Dong) of ethnic Van Kieu [5], etc... understand the suffering, struggle of the human person should have sent his son to earth to save man, to bring happiness to their lives.

Heaven also interfere with humans. These are the villains, symbolizing evil, do evil: God in the fairy tales of the nation Sau and Sia of H'mông ethnic [8] very cruel, making every effort to dissociate motherhood. God in Mr Toad of Ca Dong ethnic [5] wrong turn is the son of the rainbow, teeth, etc... down to earth to prevent and fight with people, not for them to find wives.

Fairy also belong to the Heaven. Heaven disaster symbolizes the immortal realm, dignified and was the residence of the Ngoc Hoang and the supreme deity.

In miraculous characters is Fairy: the fairy always appears very large frequency is because: "The fairy symbolizes the extraordinary ability of the spirit or of the miraculous powers of the human imagination. They performed the most bizarre 
metamorphosis and in moments can satisfy frustrated desires or higher most period. Fairies shown that human abilities that can not be wished there had, etc... Origins of fairies has roots are manifestations of mother earth. They typically show up in the mountains, near the rocky cleft cracked or near waterfalls, inside a cave, inside an abyss, on the banks of streams, groundwater, etc...” [1].

To "dream" to the heaven, humans or have reason met wife fairy, friend fairy, looking forward to immortality or meet the elves to wish "good weather".

According to the results of the author's survey, women accounted gendered Fairy number and highest frequency (167/263 times, accounting for $63,49 \%$ ) in the Fairy character is to perform dreamed about marriage - happy thousand generations of folk [3]. Fairies, beautiful fairies, etc... appear earthly guise with the animals, and then by chance encounter or distress (caught, trapped between slots boat, about to be butchered...) should was the earthly man for help, care. Touchy of the kindness and sympathy for the miserable lives, unfortunate, disadvantaged by the talented man so the fairies that sheds external guise to man. Fairies marry the mans is to repay to save lives and also help them overcome challenges, accomplish the dream of happiness, marriage.

In the story, the fairies are incredibly beautiful. They can do silly people meet from the moment the first or after dropping guise. They also have a warm heart, with loving hearts and skillful hands, like those girls on earth. Fairy became a symbol of gentle woman, the frequency of algae, suffered hard, child injured husband injured. These are the good qualities, noble woman of traditional Vietnamese in general.

Once married to people on earth, the fairies are very hard, did the housework, and her husband worried about business. They truly embody the beautiful woman beautiful streak, arch. Mermaid (Marriaget Fairy) [4] suffered very good sun and rain. Every day, she and her husband set sail fishing boat. In the Fairy snails [4], everyday, fairy left him to rely sowing, into the forest to cut wood, hunting, fishing crabs down slot. Fairy crab (Fairy crab and his fishing) [4] growing vegetables at home, weaving while the husband of the river fishing. In the imagination of the ancients about fairies, apart from extraordinary magnificence, and she also is the wife and mother living a simple life, compassionate, devoted to her husband and children.

When down to earth, there are fairies (Fisher and Princess of River King, Marriaget Fairy, Fairy toad, Fairy snails) met disaster. Was the earthly man for help, the fairies have felt the warm heart of the guy. In this case, the first feelings of supply for the mortal who was thanked by the grateful. In return humans, fairies were twinned with their centennial.

There are also many fairy tales, fairies do not appear in the forms of the animals that make their true forms as beautiful fairies, bearing angel wings (Evening Star and Morning Star, The Golden Mountain area) or shaped shaped like a beautiful girl under the earth (Heaven's return land) [9].

King of Ocean, King of River, etc... which is the symbol of the palace of the river. Humans built the miraculous characters in the water world is looking forward to the precious gift and desire to explore a miraculous world shimmering, rich with innumerable wealth, jewels, vibrant corals, colorful... usually associated with the Dragon King, King of Ocean, etc...Here, "the palace of the river meant to symbolize the source of life, is central to regeneration, eternal" [1].

The world of Deity (Gods) is also an interesting symbols in WCM: "The gods of the idealized qualities of man. The bloom of the qualities brought joy, even the destruction of the qualities that generate fear... The gods are imagined is helping people or give them weapons. But what was really to help people, it is the qualities of itself (as symbolized by the spirit of helping and harboring weapons by god gave man, etc...), the victory was due by the inherent strength of the human person" [1].

So, symbolizing divine extraordinary ability of spiritual or miraculous powers of the human imagination. They performed the most bizarre metamorphosis and in moments may disappoint or satisfy human dream. Fairy, Buddhism Buddha, etc... always meet the expectations of the people, even the evil gods, demons... they are often hampered.

The second is about grasp the intellection of the ancient art in the world, humans:

The WMC is a form of expression of the world symbols so it bears the full characteristics of that world:

Like WMC, the miraculous world in the dream filled with symbols. The miraculous world in the dream also has two layers of content means the expression of dreams and ideas behind the dream.

The content of the dream expression"is what people see and imagine during sleep. The images that can be a miraculous world, an old man, a god or even just an instruction..."Contents of expression" is often associated with sleep vague, place should human briefly elusive.

The idea implicit in the dream, 'hiding behind "the content of expression of the dream". It is the dream, the intellection of art... The WMC governs the formation, "the content of your dreams expression" of the ancients. So, the "visible" in the miraculous dream world, dream world is that the "virtual". The "miraculous" that has been used to explain, explain the "real" (the invisible) potential in it.

"The content expressed in the dream" of Ho Sinh (Miraculous pieces betel) [4] is a mandarin life, get married, have children, be put to death, etc.. This has profound roots of "underlying idea", from the dream to become concerned, life was changed earlier in Ho Sinh mind. He went into the first dream is to satisfy a dream career, then perhaps life is to see the fleeting illusion of it, etc...

To understand "the underlying idea in a dream," then he is to "decode" is "manifest content of the dream". All what the authors sending in the miraculous dream world folk is also the fairy character to experience, to explain in their dreams.

To explain for what they saw in a dream, people have used the "symbol to symbol explanation". Animated symbols that comes from the mind of man and the environment of human.

A custodian temple (No pasing the exam of the bachelor, 
menaced rank general) [4] for three times, the dream always was dreaming to see god said: "Tomorrow, you have to clean sweep the house, because having great kindness to play house". Of course, these instructions are still "closed", the god who had not let him know who it is from. Therefore, only until the next dream a third time, he would burst from new game day that he does well in a leave due. He decoded the instructions that disciple with good academic poverty but will be Heaven for doctorate, such as the Chu Sinh (Debt married in the dream) [4] dream that was given ten taels a white gold and ivory pearl, carved verses:

"Ever hundred thousand soldier

... The other paths straight marble immediately to east

... Fifteen years to meet that..."

Even when he was in the realm of dreams as well as from a dream, Chu Sinh nor how well explain the message of the dream worlds hidden behind that wording. Only when the Chu won the battle in butterfly marble, know the origin of the word "butterfly marble", see the kingdom after 15 years, the butterfly species new guy awake...

As we have analyzed above, one of the characteristics of the symbol is "simultaneity of the meaning it evokes." A malignant this has made the dream and "world symbol" coexisting in a dream - a multi-dimensional. World miraculous dream appeared simultaneously with the elements contained in it (the miraculous world, space - time, person, activities plants, god, fairy, etc...).

When conducting classifications, the author just split the content of the story relative, not separating each content dream. Likewise, the division into sub-categories such the world miraculous dream disasters government, government fisheries, etc... grave our relatively purposes only; between the realms together remains intimate relationships, transformed for one another. For example such as Debt married in the dream, beyond a dream of love, but making children dream all officialdom. He does not live in the world of butterfly species that live in the mundane. Or as in the Miraculous pieces of betel, Ho Sinh not only romantic, but also the dream was made to marry, have children, etc... Ho Sinh just live in the reality of the physical plane, just living in the world's virtual realms mong. Do which, temporarily, the researcher can only conclude that: the character would dream about what issues matter more then that would be the main content.

First is about the miraculous world such as the Heaven, the palace of River, the Limbo, etc...

Limbo is eternity for the dead, mounting with the Hades symbol, etc... Under ground was "impoundments Metamorphosis forms, revived"; "the process from death to life" [1/pg. 287]. Therefore, people usually dream to afterlife to meet again or put their loved ones on the ground (Realize mother, The white chicken and copper ring...).

The Heaven represents a veranda covered the immortal realm, dignified and was the residence of the Ngoc Hoang and the supreme deity. To "dream" to the heaven, person or have reason met first wife, you first (Strange dream, Twinning with the Dragon...) [4], or meet the gods to pray for "good weather" (The miracukous buffalo).
Person come in the Palace of River usually look forward to the precious gift and desire to explore a fantasy world shimmering, rich with innumerable wealth, jewels, corals... Interdepend with the Palace of River usually the King of River, monster under the water, transportation, etc... here spirit, "the Palace of Ocean meant to symbolize the source of life, is central to regeneration, eternal" [1/pg. 709]. Mrs Nguyen Thi Bich Chau go on water boundary and a hundred years later appeared on earth was still beautiful daughter as ever...

The earth (the underworld) and human life meant largest logo in the world miraculous dream. Although the world of suffering, poverty but still true earthly world is eternal, true life to people returning after a dream, etc...

The Deity appeared with dense frequency in the world miraculous dream and this also is a symbol system periodically interesting. Whenever human in trouble, obstacles, they expect to find out in the deity to sleep directed them to overcome difficulties. Therefore, the human had been the gods, Buddha, Fairy... help to achieve the dream (Debt maried in the dream, Gold centipede, etc...). In contrast, the supernatural force such as Giao Long, clay, god again threaten human life (The tale mountain area Dang Buoch) [10].

In the "world symbol" of the dream, the land of birds, plants (dynamic - plant) is also subject to a dream that many humans. The symbol has put on an appearance of dreams. So, the world of birds - plants which is the world of dreams has also closed is like human.

The world of birds (animals) as "a symbol of the strength of the material and the universe, matter, space, spirit" [1/pg. 316]. It is because the "primitive man felt its the same as all our fellow (which must mention animals). After this, it will acquire the ability to distinguish themselves as distinguishing the species, which is taken by the manifold disasters species as the fulcrum for disaster awareness manifold features of society " [1/pg. 319].

Animals in a dream world is diversified, tied to each type is a separate symbolic meaning.

The character of butterfly species in the country is to dream of love as Chu Sinh (Debt married of the dream). Because, "Butterflies are the symbol of happiness for the couple, for revival" [1/pg. 287].

Fish is the symbol for "life, fertility, success" [1/pg. 115]. Therefore, in the dream, K'lang (Mr K'lang and mermaid) was married with mermaid. Boy (The boy saved the people) to be consecrated god of fish, teach people how to save.

Dragon is the symbol of the emperor, the holy power, creativity. It "symbolizes the majesty of kings, gods and ensure the rhythm of life, prosperity" [1/pg. 780].

Mr Xap (Twinning with the Dragon), the man (Sword of the Dragon God) [11]... have been extraordinary strength by drinking blood Dragon, Dragon gods are trained and awarded swords etc... Dragon god shows up in the dream of the character is also very solemn and beautiful.

Birds "is synonymous with sun sign or message from heaven". Here, the miraculous beings of birds formed to highlight the slightly refined, the lift off weight of mundane. 
Bird is the image of the soul, is a symbol of the immortality of the soul. It also symbolizes the close relationship between the human spirit and act as intermediaries between the human land. This has been visible in the series (Soulmate with Babbler, The halloo: Aunt, etc...) [12].

World of plants is the "symbol for the periodicity of all forms of existence: birth, growth, death and transformed into something else. The grass plant (vegetable) is also a natural symbol of development, the forecasts will come true ", etc... [1/pg. 912].

The spinach (The tale of leeche) which is derived from vegetable species but has transformed into a beautiful guy agreed willingly to love. Dragon Tree (Bolo Khit khoc) the movement itself, turned sharply to become the Dragon god into the air...

World symbol fascinating of your dreams is to bring "intermediate characteristics" [1/XXXI]. It represents the "continuous osmosis between inside and outside". Romantic place in the realm of human beings at random, is easy thanks to the mutual penetration between space - time. System symbol do not - time in the realm of strange dreams made an "intermediary function, north of the bridge, a collection of separate elements, connecting heaven and earth, physical and spiritual, practical and dreams, waking and sleeping,"... $[1 / \mathrm{XXV}]$ from which people are free to fly back in a dream.

The world of miraculous dream is symbolic, it is also one of the categories of the "invisible". World symbol is in the center and the heart of the imaginative life. It reveals the mystery of the spiritual, provocative action of opening of the unknown and the infinite.

The world of miraculous dream belong to the invisible world as it is a place of human sleep. Sleep is the same part of the human soul so well is considered a "form" of symbol, nature "concept, highly symbolic level".

The conception of sleep and the soul had long ago. Thanks to the theory of "everything has soul" which the ancients have explained what they saw in a dream and immediately attach it to the image of the earthly world. The reason, people asleep and dreaming for then travel romantic soul. We can say, dreams are part of the human soul, and the soul is the essence - the immortal part of man. It governs and extremely complex related to the life around us.

Although humans can go into any miraculous world in the dream, it also comes from "gateway" sleep first. "Sleep" has become a miraculous method unreal, bringing people to the realm of dreams fastest. "The dream does exist for all types of characters in the world of miraculous dream, from the ultimate fairy, Buddha, holy majesty to the devil, mortals, etc... at any time. Therefore, sleep brought objective nature. Sleep "basically she cast the overall experience of the religious man, the universe, the spiritual." Sleep well make a synthetic world by showing consistency basic of the world (under the ground, on the ground and in the heaven) and finally it connects people with the world [13]

During sleep, the dream character several times, with the romantic little character; romantic character with very long but also romantic character only briefly.
Why dream frequency in each story, each character appears so high or low? The cause may be due to:

Fairy character enters repeatedly miraculous world in the dream usually directed at a content or a certain issue strung nature, connected as career, love, etc...Dream strung nature means this event followed the other events; this situation explains the different scenes. Characters can dream several times due to not satisfy their needs at right time early dreams. So dreams repeat frequency is valuable, we remind people that there has long been an aspect has not been fully resolved. The settlement of what it manifests itself through repetition frequency of dreaming will make valuable changes in quality of life of people, helping them accomplish their dreams.

The romantic character and appear only once in miraculous world in the dream is because they have received spiritual guidance of God, Fairy, Buddha, etc...Humans perform even dream with the help of assistants, etc... Go to the miraculous world in the dream once or several times, it depends on the imagination and more particularly to the artistic conception of the world of man. That means: The character goes on in dreams many times they wanted to live the moments of joy in it. Moreover, they also want to explore on their own, conquering the world that is both deeper and to see the true meaning of the earth. Humans come in a dream, used to sending miraculous world in the dream and mundane explanations, it does show the level of logical thinking human has taken a step very far. The miraculous world in the dream as myths, mysterious and complicated, suggesting it closer to the era we live better. People are no longer satisfied with the usual explanations about the world anymore. They want to experience themselves, the world discovered that not only once but several times...

General, love - marriage - happy and living life fed, fairness remain the two biggest aspiration towards the dream of human. Also, people often dream to issues of identity, career; natural desire to conquer.

Behind the images of the miraculous world in the dream, about which the author WMC folk who built the main human silhouette. Hidden behind the icon is a symbol of human miraculous characters. The symbol of human nature lively, unique, multi afternoon has been refracted in the miraculous world in the dream. Humans just where the miracullous world in the dream formed, both the creators and implementing their dreams in it. The wording in the symbol represents the human effort, in the darkness surrounding all sides try and tame guess destiny is slipping out of their hands. Therefore, "man is described as a synthesis of the world, a miniature of the universe. Man is the center of world symbol" [4/pg. 664]. Meaning logo it is the discovery of the existence of man himself, through a cosmic experience".

In addition, the human symbol was rooted in religious cult of people, from the division of the soul, part of the astral... The miraculous world in the dream fairy character is still the greatest metaphor for the human condition who, for the life and the artistic conception of the person.

It can be said, was how the miraculous world in the dream contains within itself how the human condition with 
complete different forms: someone fun, someone sad; who then agreed dream, people are disillusioned. So is the miraculous world in the dream of fun but also a world of sadness. Humans, therefore, is a mysterious universe, can not know all, incomprehensible. Although this mysterious man in a dream but is still full of people with their value base floors: status, life, ideals, life, feelings, etc... Again, people have stamped an indelible in the minds of the world concept.

Since humans became a central symbol of the miraculous world in the dream so the agency art about people, about the reason for living, happiness also appeared and surrounded it. That was the intellection of human discovery. It reflects the structure of the human personality and the corresponding complex forms in its relations with the world. "Happiness" that is the joy of being "agreed the will" of the people, even to love each other, willingly agreed to do the, wealth... wealth praised the miraculous world in the dream human love with the spiritual banquet family "full taste with varying customs"; enjoy the landscape next to the beautiful fairy, gentle as well as the desire to escape the frozen extract of feudal rites with marriage homogamy, etc... are the images associated with fate human. That human beings are not the same plate blinding, as the central image of the god, Buddha, which is the first man of real life vibrant, bitter.

Have to say, the human symbol of a system of other living symbols the miraculous world in the dream "sexy forever endless", everyone can see here what your visual ability can be realized. Lack of profound feeling and rich imagination, people would not get anything. So, the symbol of the miraculous world in the dream really is "poetic symbolism".

\section{Discussion}

General, the WMC is an interesting matter, it is quite complicated by of its rich, vivid surrounded it with cultural factors. It can be said that, WMC is a special refection method to the world, people: WMC is an object with multi factors created by ideal characters and other relative event systems. It is also a spiritual world, maiculous factors with unexpected interactions. This is also the spiritual world, interesting symbol, interfering mutation. Unexpected interaction has contributed to the change of character related to "content" and included magical functions basing on the imagination of the old people.

When studying the WMC of the dream in Vietnamese fairy-tales, the author has realized that there is a system of miraculous characters in ethnic minority fairy tales, but there isn't any miraculous characters of the dream in the fairy tales that written in verse. Maybe, it depends on type of specific versification? A way of explaining this subject is a trend of expanding this thesis's studying scope.

\section{Conclusions}

The WMC is an aesthetic world in the heart of the human subconscious. It is vast, so large that it can become indistinct, amorphous but close and humane. The reason why the wonder world has "dual" characteristics is that it is filled with the materials of Vietnam's ancient social life. The "materials" are the most quintessence and value of the real world in terms of material and spirit. All noble and deep humane things that became the traditional images in the thought of the Vietnamese were generalized, visualized into a wonderful world of the miraculous character world. The world of miraculous characters "spoke to" and "lived with ", "lived in" the images due to that reason.

\section{Acknowledgements}

The author want to express her thanks for the invitation attend The International Journal of Language and Linguistics. The author also want to express her thanks to the reviewer for his/her valuable comments and corrections of English error in the paper.

\section{References}

[1] Jean Chevalier, Alain Gheerbrant editor, Dictionary world cultural symbols, Da Nang Publishing, Nguyen Du Writing School published, 1997.

[2] Le Nguyen Can, The magic in the works of Balzac. The Education Publishing, 1999.

[3] Nguyen Thi Dung, The miraculous characters world in the Vietnammese fairy-tales. Doctoral thesis Literature, Code: 66.00102, Hanoi National University of Education, 2012.

[4] Nguyen Thi Hue edited, Tran Thi An, The collective of Vietnamese folklore. Episode 6: fairytale miraculous, Social Sciences Publishing, Hanoi, 2004.

[5] Dang Nghiem Van edited, General Literary episode of Vietnamese ethnic minorities, Episode 2: folk tales, Da Nang Publishing, 2002.

[6] Phan Dang Nhat edited, Ethnic minority literature Nghe An, Nghe An Publishing, 2001.

[7] Institute of Arts, Fairy Tales ethnic Vietnamese, Da Nang Publishing, 2000.

[8] Truong Thi Xung, Hoang Quyet collected and compiled, Tales Mong. Literature Publishing, Ha Noi, 1995.

[9] Hoang Quyet collectibles, Vietnam Northern Tales. Episode 3, Publish Vietnam North, 1976.

[10] Ta Van Thong compiled and collectibles, Tales Ma. Hanoi Culture Publishing, 1986.

[11] Ta Van Thong, Vo Quang Nhon collected and compiled, The Co ho Tales. Hanoi Culture Publishing, 1984.

[12] Hong Thang compose collectibles and recruitment, Tales Vietnam, Set the 1B, Social Sciences Publishing, Hanoi, 1983.

[13] Do Huy, Establishment of cultural philosophy Vietnam Arts. Institute of Culture, the Culture and Information Publishing, Hanoi, 2002. 